\title{
BCciv4
}

\section{INFLUENCE OF LOW CONTENT OF STEEL FIBRE ON CONCRETES PRODUCED WITH RECYCLED COARSE AGGREGATES WITH DIFFERENT LEVELS OF DENSITY}

\author{
$\underline{\text { Antonio D. de Figueiredo }}{ }^{(1)}$, Ivie Pietra ${ }^{(2)}$ and Luís A. G. Bitencourt Jr. ${ }^{(3)}$ \\ (1) Department of Civil Construction Engineering, University of São Paulo, Brazil \\ (2) Joy Congero Constructions, Brazil \\ (3) Department of Structural and Geotechnical Engineering, University of São Paulo, Brazil
}

https://doi.org/10.21452/bccm4.2018.02.26

\begin{abstract}
When construction and demolition (C\&D) waste is applied in concrete as aggregate, its porosity leads to a concrete with a reduced strength. Normally, this drawback induces to mixdesigns with higher cement contents in order to compensate the strength reduction, which also increases the environmental impact of the material. The experimental study carried out in this work demonstrates that the flexural strength reduction is diminished with steel fibres reinforcement. This condition could compensate this drawback for some applications where the use of fibres is already forecasted. Recycled C\&D aggregates with different density levels were produced to be added in concrete with different steel fibres contents. The experimental and numerical results demonstrate that the reduction of C\&D aggregates oven-dry (OD) density will lead to a reduction on compressive strength without any influence of the fibres. Instead, the use of steel fibres could mitigate the flexural strength decrease. The performance of the concrete with recycled aggregates were approximated to the conventional concrete when the fibre content was increased on the first one. The behaviour was even closer when the w/c ratio was higher and the matrix strength was reduced for both types of concrete.
\end{abstract}

\section{INTRODUCTION}

Some of the essential aspects of sustainable development are the actions focusing the environment preservation and conservation of the rapidly diminishing ordinary resources. In that sense, efforts have been historically made, by trying to find out viable applications for construction and demolition (C\&D) waste in order to avoid its disposal [1,2].

Normally, the use of C\&D recycled aggregates will reduce the concrete strength proportionally to the aggregates density [3]. Normally, the decrease in the strength will be considered a problem that requires an increase in cement consumption or improve the aggregates through treatments. Both of them are responsible for increasing costs and environmental impacts. In that sense, some recent studies have been carried out in order to turn viable the use of steel fibre reinforced recycled coarse aggregate concrete (SFRRCAC) [4]. 
Nevertheless, this research was not conclusive about the flexural strength due to some limitations of the experimental study.

The study of Gao \& Zhang [5], focusing the analysis of SFRRCAC flexural performance, was also non-conclusive when low contents of steel fibre (less than $0.5 \%$ ) were used, defining the behaviour of the material as non-obvious. In that sense, an experimental study was developed in order to better understand the behaviour of SFRRCAC varying the aggregate density. The main objective of the study is to establish relations between the matrix characteristics and the effect of steel fibre reinforcement on the flexural strength of the composite. In addition, numerical analyses are carried out in order to better understand the influence of the fibres on the composite behaviour for some mixtures considered in this research.

\section{EXPERIMENTAL PROGRAM}

\subsection{Recycled aggregates preparation}

The experimental study was performed based on the possibility of variation of the coarse aggregates density. The processing of recycled aggregates aimed the separation in different bands of density. This separation can be performed through heavy media separation, which is a process applied to the separation of minerals according to their densities by the use of organic liquids, solutions of inorganic salts or stable suspension of pre-determined density.

A sample of about one cubic meter of recycled aggregate was obtained from the Itaquera Recycling Plant located in the city of São Paulo, Brazil. The aggregates were produced by crushing C\&D waste in a primary impact crusher. The retained $19.1 \mathrm{~mm}$ fraction was crushed again in a lab jaw crusher to fit the specified particle size distribution. The aggregates were sieved, and the fraction below $9.5 \mathrm{~mm}$ was discarded in order to provide similar mixture conditions to the ordinary crushed stone aggregate. Then, the coarse fraction (19.1-9.5 mm) was washed in order to remove any fine particles adhering to outer surfaces. The fraction was then dried on a ventilated oven at $110^{\circ} \mathrm{C}$ for $24 \mathrm{~h}$.

The C\&D aggregates were prepared for the experimental program through a classification into 2 classes according to their porosity by sink-and-float procedure. The sink-float technique turns possible $C \& D$ aggregate particles separation into different OD density classes [3]. Therefore, this procedure turns possible to analyse the influence of the aggregates density in the composite behaviour. The equipment used in this experimental study is the same used by Angulo et al. [3]. The sink and float separation provided two ranges of specific weight: between 1.9 and $2.2 \mathrm{~g} / \mathrm{cm}^{3}$, and between 2.2 and $2.5 \mathrm{~g} / \mathrm{cm}^{3}$. The phase composition (cement based, ceramic, ordinary rocks) of each density class was determined by hand sorting and the result is presented in Table 1.

The characterization of the recycled aggregate is presented in Table 2 together with the ordinary coarse aggregate. The determination of the OD densities of coarse aggregates follow the Equation (1). The recycled aggregates were pre-saturated for 10 minutes in water to prevent the aggregate influence in concrete's water demand [6,7].

ODdensity $=\mathrm{Md} \div(\mathrm{MSSD}-\mathrm{MW})$

where,

ODdenstity is the density in $\mathrm{kg} / \mathrm{dm}^{3}$;

Md is the aggregate mass dried at $110^{\circ} \mathrm{C}$ for $24 \mathrm{~h}(\mathrm{~kg})$;

MSSD is the mass at saturated surface-dry (SSD) condition (kg), and

MW is the mass under water $(\mathrm{kg})$.

Table 1: Characteristics of recycled aggregates used in the experimental program 


\begin{tabular}{ccc}
\hline Phase & $\begin{array}{c}1.9<\mathrm{d}<2.2 \\
(\%)\end{array}$ & $\begin{array}{c}2.2<\mathrm{d}<2.5 \\
(\%)\end{array}$ \\
\hline Concrete and mortar & 92.37 & 53.15 \\
Red ceramic & 2.43 & 0.18 \\
White ceramic & 2.81 & 0.17 \\
Granite & 0.48 & 44.91 \\
\hline Bitumen & 1.73 & 1.59 \\
\hline Asbestos & 0.18 & 0.00 \\
\hline Total & 100.00 & 100.00 \\
\hline $\mathrm{d}=$ density $\left(\mathrm{g} / \mathrm{cm}^{3}\right)$ & &
\end{tabular}

\subsection{Ordinary materials}

The ordinary crushed aggregate (granite), ordinary quartz river sand, Portland cement blended with roughly 35\% blast furnace slag (CP II E type with a 28-day compressive strength of $32 \mathrm{MPa}$ ) and the dispersion admixture (Lignosulfonate) were obtained from the local market. The hooked end fibres used were produced from cutting steel sheet (fibre type A II according to Brazilian standard ABNT NBR 15530:2007), and also obtained in local market. The average yield strength of the fibres was $600 \mathrm{MPa}$ with a length of $49 \mathrm{~mm}$ and rectangular cross section of $0.45 \mathrm{~mm}$ by $1.84 \mathrm{~mm}$ as informed by the producer.

Table 2: Composition of recycled aggregates used in the experimental program

\begin{tabular}{cccc}
\hline Coarse Aggregate & $\begin{array}{c}\text { Recycled } \\
1.9-2.2 \mathrm{~g} / \mathrm{cm}^{3}\end{array}$ & $\begin{array}{c}\text { Recycled } \\
2.2-2.5 \mathrm{~g} / \mathrm{cm}^{3}\end{array}$ & Ordinary \\
\hline Density $\left(\mathrm{g} / \mathrm{cm}^{3}\right)$ & 2.07 & 2.50 & 2.63 \\
\hline Water absorption $(\%)$ & 6.75 & 2.16 & 0.03 \\
\hline Maximum size $(\mathrm{mm})$ & 19 & 19 & 19 \\
\hline
\end{tabular}

\subsection{Concrete mix proportions}

The matrix mix-design was performed using the same method used by other Brazilian researchers [8] to evaluate the efficiency of recycled aggregate in plastic concretes with respect to its mechanical strength and durability, by maintaining the same workability conditions [9]. In this method, the optimum mortar proportion is determined in terms of dry materials $(\alpha)$ according to Equation (2). This determination was made for each range of density of recycled aggregate and for the ordinary aggregate. The $\alpha$ determination is normally done by visual evaluation. The optimum $\alpha$ is the minimum that provides to concrete a smooth aspect when the 
slump cone mould is removed. The $\alpha$ value is reported as the responsible for the concrete cohesive characteristics and could be related to the volume of mortar responsible to fill up the coarse aggregate voids. Consequently, it will depend on aggregates characteristics. Once $\alpha$ value is determined, this value is kept constant for all mixtures in the study. A similar approach was adopted by other researchers as the equivalent mortar volume method [10] for recycled aggregate concretes. This approach allows keeping constant the relative volume proportion of mortar to coarse aggregates in concrete. In this particular case, the constant volume of coarse aggregates will avoid the influence of different aggregate densities in the mix-proportions. Table 3 presents the results of an optimum mortar obtained for each coarse aggregate.

$\alpha=(1+a) /(1+a+b)$

where,

$\alpha=$ mortar content in terms of dry materials;

$\mathrm{a}=$ fine aggregate mass proportion to cement;

$\mathrm{b}=$ coarse aggregate mass proportion to cement.

One of the fundaments of this method is to produce three concretes with the same workability conditions (fixed slump and mortar content), by varying the cement content. Therefore, three concrete mix proportions where produced adjusting the amount of water to obtain a consistency in the slump range of $80 \pm 10 \mathrm{~mm}$ for all of them. Thus, it was defined families of concretes with constant consistency and mortar content, but with three different cement contents and w/c ratios. For each matrix obtained, it was used the following steel fibre contents: $0,10,20$ and $40 \mathrm{~kg} / \mathrm{m}^{3}$. Where the addition of fibres has incurred loss of slump, water consumption was adjusted to yield a slump equal to $80 \pm 10 \mathrm{~mm}$. The slump was measured by the usual slump testing.

Table 3: Optimum mortar $(\alpha)$ for each coarse aggregate used

\begin{tabular}{cccc}
\hline Coarse Aggregate & $\begin{array}{c}\text { Recycled } \\
2.07 \mathrm{~g} / \mathrm{cm}^{3}\end{array}$ & $\begin{array}{c}\text { Recycled } \\
2.50 \mathrm{~g} / \mathrm{cm}^{3}\end{array}$ & $\begin{array}{c}\text { Ordinary } \\
2.63 \mathrm{~g} / \mathrm{cm}^{3}\end{array}$ \\
\hline$\alpha$ & $54 \%$ & $52 \%$ & $48 \%$ \\
\hline
\end{tabular}

\subsection{Specimens cast and testing}

For each mixture, the specific gravity weight of the concrete was measured in fresh state using a recipient with a known volume. For each mixture five cylindrical specimens $(10 \times 20$ $\mathrm{cm}$ ) were produced from a single batch in order to measure compressive strength and water absorption. Compressive strengths tests were performed in a $2000 \mathrm{kN}$ hydraulic Shimadzu ${ }^{\circledR}$ testing machine. For this test, three cylindrical specimens were tested for each mix composition. For each mixture, four prismatic specimens $(10 \times 10 \times 40) \mathrm{cm}^{3}$ were also produced in order to obtain the flexural strength values, using the same test machine. All the casted specimens remained in their moulds for 24 hours. The specimens were cured in a moist chamber with a temperature of $23 \pm 2{ }^{\circ} \mathrm{C}$ and relative humidity equal or greater than $95 \%$ for 28 days. Finally, the specimens were tested at the age of 28 days.

\section{NUMERICAL ANALYSES}

Numerical Analyses were performed to verify the contribution of the fibres on the flexural behavior of the composite with recycled coarse aggregates $\left(2,07 \mathrm{~g} / \mathrm{cm}^{3}\right)$ and ordinary crushed aggregates $\left(2,63 \mathrm{~g} / \mathrm{cm}^{3}\right)$. Figure 1 illustrates the numerical model constructed using a discrete and explicit representation of the fibres, as proposed by Bitencourt Jr. [11], for steel fibre contents of $40 \mathrm{~kg} / \mathrm{m}^{3}$. It important to mention that the aggregates are homogenised in the matrix and the effective mechanical properties are evaluated using the mixture theory in order to consider the porosity of these inclusions. 


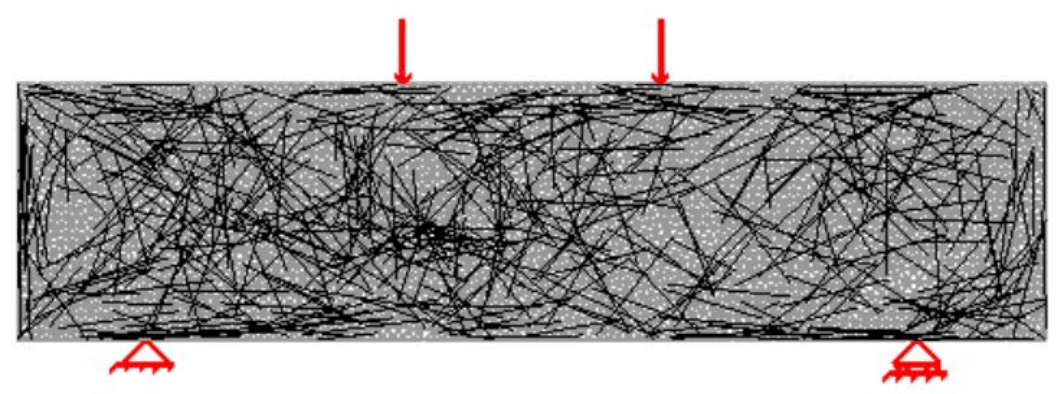

Figure 1: Numerical model to study the contribution of the fibres on the flexural behaviour of the composite

The steel fibres are modelled using two-node finite elements (truss elements) with an elastic perfectly plastic constitutive model with Young's modulus of 210GPa and yield stress of $1200 \mathrm{MPa}$. They are positioned using an uniform isotropic random distribution, considering the wall effect of the mold.

A continuum damage model with two independent scalar damage variables is applied to describe the concrete behaviour under tension and compression. Three-node triangular finite element is used in the discretization of the concrete in finite elements. The material parameters adopted are listed in Table 4.

Table 4: Parameters adopted for the concrete in the numerical analyses

\begin{tabular}{ccc}
\hline & $\begin{array}{c}\text { Recycled } \\
2.07 \mathrm{~g} / \mathrm{cm}^{3}\end{array}$ & $\begin{array}{c}\text { Ordinary } \\
2.63 \mathrm{~g} / \mathrm{cm}^{3}\end{array}$ \\
\hline Young's modulus (MPa) & 21000 & 35000 \\
\hline Poisson's ratio & 0.2 & 0.2 \\
\hline Fracture energy (N/mm) & 0.15 & 0.15 \\
\hline Tensile strength (MPa) & 2.10 & 2.88 \\
\hline Compression stress damage & 21.0 & 28.8 \\
threshold (MPa) & 0.89 & 0.89 \\
\hline Compressive parameter $\mathrm{A}^{-}$ & 1.16 & 1.16 \\
\hline Compressive parameter B & & \\
\hline
\end{tabular}

The concrete-fibre interaction is described by a non-rigid coupling scheme proposed by Bitencourt Jr. [11] by adopting an appropriate constitutive damage model to describe the relation between the shear stress (adherence stress) and the relative sliding between the concrete and each fibre individually. In Table 5 are listed the material parameters adopted.

Table 5: Parameters adopted for the concrete-fibre interaction in the numerical analyses

\begin{tabular}{ccc}
\hline & $\begin{array}{c}\text { Recycled } \\
2.07 \mathrm{~g} / \mathrm{cm}^{3}\end{array}$ & $\begin{array}{c}\text { Ordinary } \\
2.63 \mathrm{~g} / \mathrm{cm}^{3}\end{array}$ \\
\hline Maximum shear stress (MPa) & 12.0 & 12.0
\end{tabular}


$4^{\text {th }}$ Brazilian Conference on Composite Materials. Rio de Janeiro, July $22^{\text {nd }}-25^{\text {th }}, 2018$

\begin{tabular}{ccc}
\hline Residual shear stress (MPa) & 4.5 & 4.5 \\
\hline Alpha & 0.4 & 0.4 \\
\hline Slip s $1(\mathrm{~mm})$ & 0.01 & 0.01 \\
\hline Slip s $(\mathrm{mm})$ & 6.5 & 6.5 \\
\hline $\begin{array}{c}\text { coupling constant (normal) } \\
(\mathrm{MPa} / \mathrm{mm})\end{array}$ & $10^{9}$ & $10^{9}$ \\
\hline $\begin{array}{c}\text { coupling constant (tangential) } \\
(\mathrm{MPa} / \mathrm{mm})\end{array}$ & $10^{3}$ & $10^{3}$ \\
\hline
\end{tabular}

More details about the numerical model employed can be found in Bitencourt Jr. [11].

\section{RESULTS AND DISCUSSION}

\subsection{Compressive strength}

The obtained results show that the compressive strength does not change with increasing content of steel fibres. Therefore, the fibre content will be ignored in the analysis of compressive strength. On the other hand, the w/c ratio is clearly a strong influence on compressive strength, as can be seen in Figure 2, where Abram's Law curves obtained for each type of aggregates are presented. In this figure is possible to observe that the behaviour of the concretes with ordinary aggregates and recycled with $2.50 \mathrm{~g} / \mathrm{cm}^{3}$ envelop density were very close. The mixtures produced with recycled aggregates with $2.07 \mathrm{~g} / \mathrm{cm}^{3}$ presented a reduced level of strength for lower level of w/c ratio. When w/c ratio used was higher than 0.6 , the performance of the mixtures became close. When the w/c ratio is higher, the porosity of the recycled aggregates ceases to be critical and the porous cement paste controls the fracture of the material.

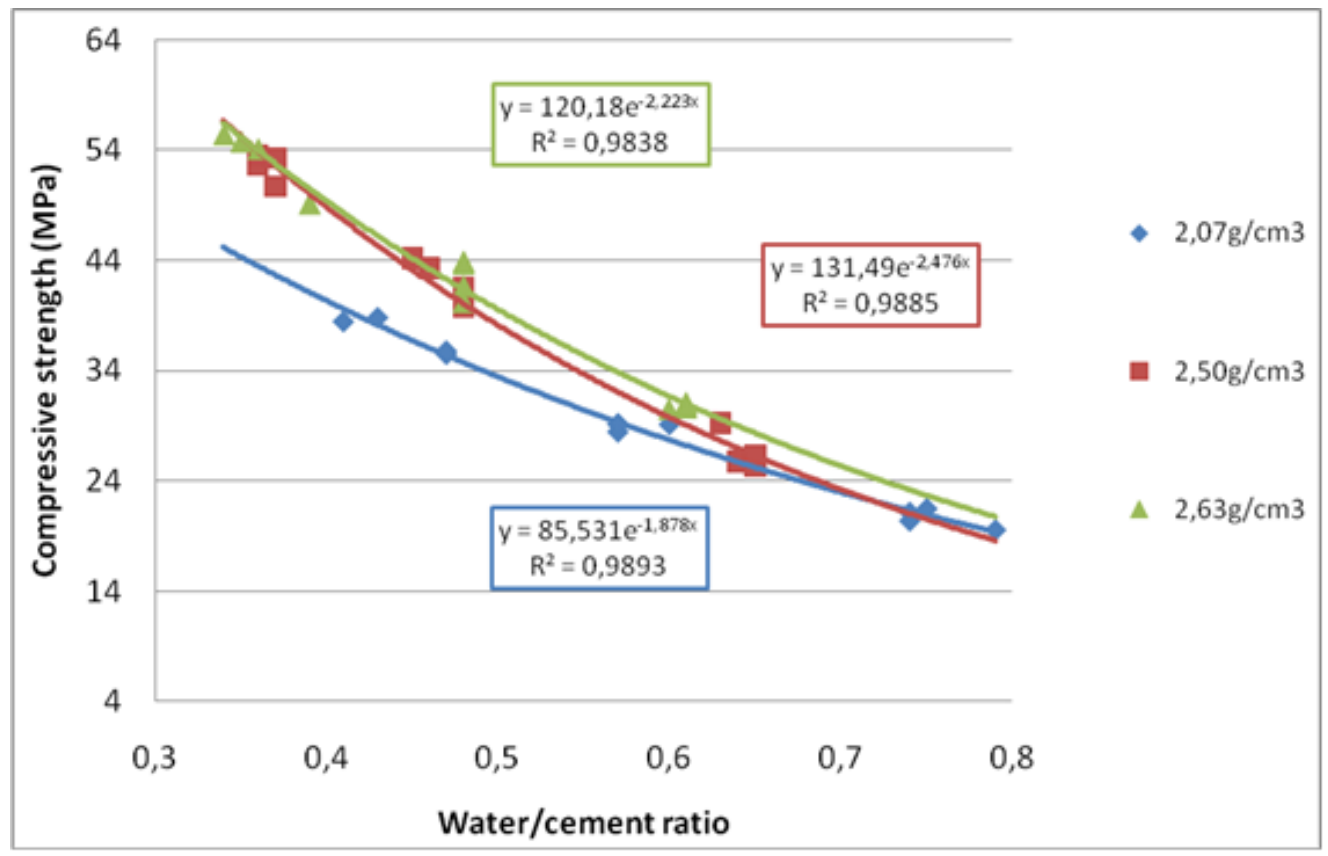


Figure 2: Correlation between the water absorption and w/c ratio for all types of coarse aggregates

\subsection{Flexural strength and numerical simulation}

In Figure 3, the correlation between the results of the flexural strength and the w/c ratio is presented for each coarse aggregate density class and each fibre consumption for an overall visualization of the behaviour. For flexural strength, the fibres showed an opposite behaviour to the compressive strength, and clearly demonstrate an effect in the results in combination with the coarse aggregate density class. For mix proportions with ordinary coarse aggregate (continuous lines), the increase in the steel fibre content did not influence the flexural strength. However, for mix proportions with recycled coarse aggregate, the flexural strength was increased proportionally to the fibre contents. This increase is more intense for the recycled aggregates with envelop density of $2.03 \mathrm{~g} / \mathrm{cm}^{3}$ (dotted lines) and low levels of w/c ratio. This pattern is the same observed in the study of KAYALI et al. [12] for lightweight concrete. The mixtures with envelop density of $2.50 \mathrm{~g} / \mathrm{cm}^{3}$ presented an intermediate behaviour, but closer to the mixtures produced with ordinary aggregates.

The scatter of the results was greater when lower the w/c ratio used. In this case, the better adhesion of the fibre to the cement paste provided a greater ability to reinforce the system to inhibit the crack propagation. This condition brought the behaviour of the concrete with recycled aggregates closer of ordinary concrete as the fibre content was increased. On the other hand, for higher w/c ratios, the critical condition for defining the behaviour is the low paste strength. In this situation, the scatter of the results is smaller, similarly to the contribution of the fibre. This lower contribution of the fibre results from the decrease in its tensile transfer capacity due to the increase in the porosity of the paste. Contrary to the observed for compressive strength, it is possible to affirm that steel fibres help to minimize the reducing effect of flexural strength provided by the use of recycled aggregates.

The numerical simulation generated values of flexural strength very close to the experimental ones for the concretes of lower w/c ratio. In the case of ordinary aggregates, the simulation provided flexural strengths of 6.5 and $6.6 \mathrm{MPa}$ for concretes with 0 and $40 \mathrm{~kg} / \mathrm{m}^{3}$ of fibres, respectively. These values are very close to those obtained experimentally which corresponded to $6.5 \pm 0.7 \mathrm{MPa}$ and $6.4 \pm 0.2 \mathrm{MPa}$. The simulation for concretes with aggregates with lower density produced flexural strengths of 4.6 MPa and 5.1 MPa for fibre consumption of 0 and $40 \mathrm{~kg} / \mathrm{m}^{3}$, respectively. These values were also very close to the average test results of 4.3 $\pm 0.1 \mathrm{MPa}$ and $4.9 \pm 0.5 \mathrm{MPa}$. The flexural strength gain obtained with the fibres was about $10 \%$ and $14 \%$ for the numerical simulation and experimental results, respectively, proving that the fibres contribute to minimize the strength reduction generated by the use of more porous recycled aggregates. 


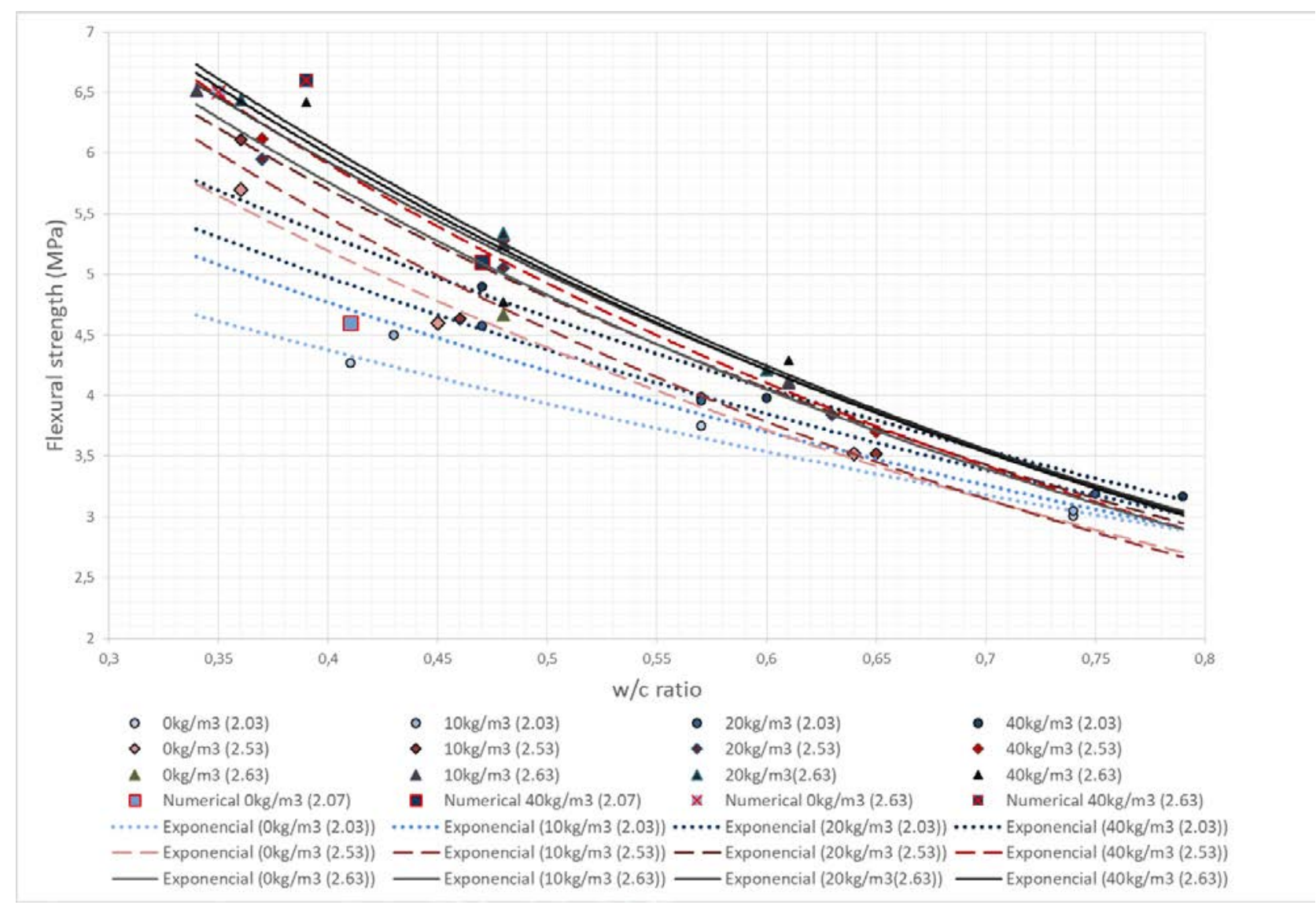

Figure 3: Flexural strength versus w/c ratio for all mix proportions with recycled and ordinary coarse aggregate

\section{CONCLUDING REMARKS}

The use of recycled C\&D aggregates with envelope density closer to the ordinary aggregates bring minor reductions to the composite performance. The total replacement of ordinary aggregates by C\&D recycled aggregate with envelope density of $2.50 \mathrm{~g} / \mathrm{cm}^{3}$ shows similar performance to the reference concrete. This finding is very similar to the results obtained by Choi \& Yun [13] using a recycled aggregate with an envelope density of greater than 2.50 $\mathrm{g} / \mathrm{cm}^{3}$. In this case, steel fibre contents higher than $20 \mathrm{~kg} / \mathrm{m}^{3}$ allow to SFRRCAC to present equivalent flexural behaviour to ordinary SFRC.

The reduction in flexural strength was more intense for the $C \& D$ aggregates with lower density $\left(2.07 \mathrm{~g} / \mathrm{cm}^{3}\right)$, which is more intense when the recycled aggregates present higher level of porosity and, also, when low levels of w/c ratio are used. In this case, the use of steel fibre provides an approximation of the behaviour between ordinary SFRC and SFRRCAC. For w/C ratio higher than 0.6, the matrix flexural strength has no significant influence of the aggregates porosity and the fibre might not be effective because the cement paste is not dense enough to provide better conditions to stress transfer to the fibre. These findings where confirmed by numerical analysis and test results. The fibre contribution could be interesting in order to reduce the cement demand to enhance the strength of concretes made with $C \& D$ waste recycled aggregates in order to minimize the reduction in the flexural strength, a property usually found in applications such as pavements. 


\section{REFERENCES}

[1] OIKONOMOU, N. D. Recycled concrete aggregates, Cement \& Concrete Composites. 27 (2005), 315-318.

[2] RAO, A., JHA.K. N., MISRA, S. Use of aggregates from recycled construction and demolition waste in concrete. Resources, Conservation and Recycling 50 (2007) 71-81.

[3] ANGULO, S. C.; CARRIJO, P. M.; FIGUEIREDO, A. D.; CHAVES, A. P. JOHN, V. M. On the classification of mixed construction and demolition waste aggregate by porosity and its impact on the mechanical performance of concrete. Materials and Structures 43 (2010) 519528.

[4] AHMADI, M.; FARZIN, S., HASSANI, A.; MOTAMEDI, M. Mechanical properties of the concrete containing recycled fibres and aggregates. Construction and Building Materials 144 (2017) 392-398;

[5] GAO, D., ZHANG, L. Flexural performance and evaluation method of steel fiber reinforced recycled coarse aggregate concrete. Construction and Building Materials 159 (2018) 126-136

[6] POON, C.S.; SHUI, Z.H.; LAM, L.; FOK, H.; KOU, S.C. Influence of moisture states of ordinary and recycled aggregates on the slump and compressive strength of concrete. Cement and Concrete Research 34 (2004) 31-36.

[7] GÓMEZ-SOBERÓN J. Porosity of recycled concrete with substitution of recycled concrete aggregate - an experimental study. Cement and Concrete Research 32 (2002) 1301- 1311.

[8] LEVY S. M, HELENE P. Durability of recycled aggregates concrete: a safeway to sustainable development. Cement Concrete Research. 34 (11) (2004) 175-180.

[9] FIGUEIREDO, A. D.; CECCATO, M. R. Workability Analysis of Steel Fibre Reinforced Concrete Using Slump and Ve-Be Test. Materials Research, 18 (2015), p. 1284-1290.

[10] ABBAS, A. et al. Durability of recycled aggregate concrete designed with equivalent mortar volume method. Cement \& Concrete Composites. 31 (2009) 555-563

[11] BITENCOURT JR., L. A. G. (2015) Numerical modelling of failure processes in steel fiber reinforced cementitious materials. Ph.D. Thesis. Polytechnic School, University of São Paulo.

[12] KAYALI, O.; HAQUE, M.N.; ZHU, B. Some characteristics of high strength fibre reinforced lightweight aggregate concrete. Cement \& Concrete Composites. 25 (2003) 207-213.

[13] CHOI, W., YUN, H., Long-term deflection and flexural behavior of reinforced concrete beams with recycled aggregate, Mater. Design. 51 (2013) 742-750. 